IJzermans, J., Soeteman, R. Gezondheidsproblemen en zorggebruik na drie rampen in Nederland: monitoring in de huisartspraktijk. Psychologie \& Gezondheid: 2008, 36(3), 141-146

\begin{tabular}{|l|l|}
\hline Postprint Version & 1.0 \\
\hline Journal website & http://vb23.bsl.nl/frontend/index.asp?custom_product_id=1873-1791 \\
\hline Pubmed link & \\
\hline DOI &
\end{tabular}

This is a NIVEL certified Post Print, more info at http://www.nivel.eu

\title{
Gezondheidsproblemen en zorggebruik na drie rampen in Nederland: monitoring in de huisartspraktijk
}

\author{
JORIS IJZERMANS EN RIK SOETEMAN* \\ * Joris IJzermans is programmaleider (programma 'Acute zorg \& Rampen') bij het \\ Nederlands Instituut voor onderzoek van de gezondheidszorg (NIVEL); Rik Soeteman is \\ huisarts in Enschede. \\ Correspondentieadres : Dr. C.J. IJzermans, NIVEL, Postbus 1568, 3500 BN Utrecht. \\ E-mailadres: j.Yzermans@nivel.nl.
}

\section{HEALTH PROBLEMS AND UTILIZATION IN THE AFTERMATH OF THREE DISASTERS IN THE NETHERLANDS: SURVEILLANCE IN GENERAL PRACTICE}

In the Netherlands, every citizen is obliged to be enlisted by one general practitioner (GP), who acts as a gatekeeper to secondary care. GPs register all patient and morbidity data in Electronic Medical Records (EMR). After disasters it is important to optimize the specific care for survivors, especially in primary care. That is why in the Netherlands the EMRs are used to survey (patterns of) utilization and health problems related to the disaster longitudinally. It is possible to obtain baseline data from the period before the disaster, there is no 'recall bias' and surveillance is no burden for the survivors. In this paper, the use of existing registries after disasters is illustrated by an overview of the study designs and major results of surveillance after three disasters in the Netherlands: a plane crash in Amsterdam (1992), the explosions of a fireworks depot in a residential area in Enschede (2000) and a café fire in Volendam (2001).

\section{INLEIDING}

De huisarts neemt in het Nederlandse gezondheidszorgsysteem een centrale rol in. Organisatorisch omdat hij poortwachter is naar de tweede lijn en burgers verplicht staan ingeschreven bij één huisartspraktijk. Inhoudelijk omdat hij de patiënt en diens ziektegeschiedenis kent - en digitaal heeft vastgelegd - en een onderscheid weet te maken tussen wat 'pluis' en 'niet pluis' is. De huisarts is, in tijden van crisis, de spin in het web van de nazorg, zoals bleek na de laatste twee grote Nederlandse rampen in de Bijlmermeer en Enschede en na de brand in Volendam. In de huisartspraktijk kan goed worden gevolgd hoe het met de getroffenen gaat, op het terrein van gepresenteerde klachten en ziektes, van kwaliteit van leven en van zorg- en medicatiegebruik. Vanaf de Bijlmerramp is er daarom onderzoek gedaan naar de gevolgen van de ramp voor getroffen huisartspatiënten. Daarbij heeft dit type onderzoek een ontwikkeling doorgemaakt waarvan in dit artikel verslag wordt gedaan: er wordt per ramp geschetst hoe onderzoek werd opgezet en uitgevoerd en wat de voornaamste uitkomsten waren. 
IJzermans, J., Soeteman, R. Gezondheidsproblemen en zorggebruik na drie rampen in Nederland: monitoring in de huisartspraktijk. Psychologie \& Gezondheid: 2008, 36(3), 141-146

\section{BIJLMERRAMP}

\section{Onderzoeksopzet}

Onderzoek naar de gevolgen van de Bijlmerramp (oktober 1992) voor de gezondheid werd pas na $5 \frac{1}{2}$ jaar opgestart, in de lente van 1998. De lezer zal zich herinneren dat de nasleep van deze ramp lang en weerbarstig was, er was een 'ramp na de ramp' (Gersons, Carlier, \& IJzermans, 2000; Vasterman, Yzermans, \& Dirkzwager 2005; Yzermans \& Gersons 2002). Getroffenen attribueerden hun gezondheidsproblemen aan het meemaken van de ramp, de lading van de El Al Boeing was niet bekend en de nasleep was steeds (ook politiek) in het nieuws, culminerend in een Parlementaire Enquête. Het AMC kreeg de opdracht om de aard en omvang van de klachten in kaart te brengen. Daartoe werden drie acties uitgevoerd:

- $\quad$ alle huisartsen in Amsterdam Zuidoost werden geïnterviewd;

- een telefonisch meldpunt werd ingesteld waar mensen hun klachten konden doorgeven;

- deze doorgegeven klachten werden verzonden naar huisartsen ter verifiëring in de medische dossiers.

\section{Resultaten}

Er werden 51 (van de 56) huisartsen geïnterviewd over het aantal mensen in hun praktijk dat, direct of indirect, gezondheidsgevolgen van het meemaken van de ramp had. Er werd geschat dat 250 van hun 92.000 patiënten direct getroffen waren. Voor nog eens 300 mensen werd een indirect verband gezien tussen de ramp en hun gezondheidsproblemen, meestal psychische problemen. Bij deze laatste groep ging het vooral om mensen die hun gezondheidsproblemen zelf aan de ramp attribueerden. Meer over het algemeen komt deze tweedeling na rampen steeds terug, mede omdat er geen definitie is van het begrip 'getroffene': wie is direct door de ramp getroffen en wie vindt zelf dat zijn gezondheidsproblemen aan de ramp zijn toe te schrijven? In de hectiek van het moment wordt niet goed bijgehouden wie getroffen was, wie waar was op welk moment of in welke relatie men stond tot slachtoffers.

Ruim 800 mensen belden hun klachten (gemiddeld vier per persoon) door aan het telefonisch meldpunt. Moeheid was de belangrijkste klacht, naast benauwdheid en hoofdpijn. Aan de bellers werd gevraagd of zij de Symptom Checklist 90 (SCL-90) wilden invullen en er werd gevraagd met een schriftelijk informed consent of het medisch dossier bij de eigen huisarts mocht worden opgevraagd. De totaalscores van de SCL-90 weken gemiddeld twee standaarddeviaties af van die van de gemiddelde Nederlander: een duidelijk teken van distress. Op het niveau van de subschalen van de SCL ging het daarbij vooral om 'somatische klachten' en 'depressie'. Vooral mannelijke, allochtone respondenten uit de getroffen flats vormden zes jaar na de ramp een risicogroep (Donker, Yzermans, Spreeuwenberg, \& Van der Zee, 2004; IJzermans et al., 1999).

Het medisch dossieronderzoek had betrekking op 65\% van de bellers, waarvoor contact werd opgenomen met 345 huisartsen. De non-respons werd hier vooral veroorzaakt doordat respondenten geen schriftelijke informed consent terugzonden. De meerderheid van de aan het meldpunt doorgegeven klachten (74\%) bleek bij de huisarts bekend, waarvan $11 \%$ al van voor de ramp en nog eens $15 \%$ van de periode van de mediahype rond deze ramp, winter 1998/99. Slechts in 6\% van de gevallen werd door de huisartsen een directe relatie verondersteld tussen klacht en ramp; een relatie die al helemaal niet werd gezien voor 'harde' diagnoses, zoals kanker en auto-immuun aandoeningen (Donker, Yzermans, Oosterhek, Spreeuwenberg, \& Van der Zee 2002).

Door de onderzoekers werd geconcludeerd dat gezondheidsproblemen vooral werden toegeschreven aan de ramp en er niet - direct - door werden veroorzaakt. De overheid besloot een vangnet op te zetten voor de getroffenen met een Posttraumatisch Stress Syndroom en/of met lichamelijk onverklaarde klachten. Toch kreeg iedereen die zichzelf als getroffene beschouwde recht op uitgebreid medisch onderzoek en vond epidemiologisch 
IJzermans, J., Soeteman, R. Gezondheidsproblemen en zorggebruik na drie rampen in Nederland: monitoring in de huisartspraktijk. Psychologie \& Gezondheid: 2008, 36(3), 141-146

onderzoek plaats onder politie en brandweer. De resultaten van dit laatstgenoemde onderzoek bevestigden de eerdere resultaten van het AMC-onderzoek: het ging vooral om onverklaarde symptomen en psychische problemen.

\section{VUURWERKRAMP ENSCHEDE}

\section{Onderzoeksopzet}

Na de Vuurwerkramp van 13 mei 2000 werden de lessen van de (lange nasleep van de) Bijlmerramp omgezet in pro-actief beleid. Eén van de beslissingen was om onderzoek uit te voeren waarbij gebruik werd gemaakt van het bestaande registratiesysteem van de huisarts, een project dat uiteindelijk een looptijd tot vijf jaren na de ramp zou hebben. Nagenoeg alle huisartsen in Enschede werkten vanaf 1999 met elektronische medische dossiers. Dat maakte het mogelijk om de onderzoeksperiode te beginnen 1,4 jaar voor de ramp, waardoor pre-post vergelijkingen konden worden gemaakt. Niet-getroffen mensen uit de deelnemende huisartspraktijken golden als referentiegroep. De keuze voor een dergelijke samenstelling van de vergelijkingsgroep werd vooral gemaakt om interdoktervariatie (met name variatie in registratiegedrag) en culturele verschillen te vermijden. Bovendien stonden privacyregels in de weg om elders een controlegroep samen te stellen; extraheren van gegevens van voor de ramp stuitte voor een controlegroep op grotere bezwaren dan voor de getroffen groep. Tenslotte menen wij dat niet-getroffen bewoners van eenzelfde stad nauwelijks aan de ramp gerelateerde gezondheidsproblemen ervaren, hoezeer Amerikaanse onderzoekers ons na ' $9 / 11$ ' ook van het tegendeel proberen te overtuigen. Bij analyse bleek de referentiegroep op de meeste punten meer op de Nederlandse bevolking te lijken dan op de getroffenen (IJzermans, Dirkzwager, Kerssens, Cohen-Bendahan, \& Ten Veen, 2006).

Nederlandse huisartsen gebruiken de International Classification of Primary Care (ICPC, Lamberts \& Wood, 1987), een meer-assig classificatiesysteem waarin niet alleen diagnoses worden geregistreerd, maar ook klachten (in de woorden van de patiënt).

Het commitment van de huisartsen om mee te werken werd relatief snel verkregen: driekwart van hen deed mee, waardoor $89 \%$ van de getroffenen kon worden gemonitord. Onder de niet-meewerkende huisartsen kwamen vooral artsen voor die geen of slechts een enkele getroffene hadden ingeschreven in de praktijk.

De start van het project kende enige vertraging. De financiering van het project liet op zich wachten en er moest een manier gevonden worden om met privacy-aspecten om te gaan. Dat laatste was vooral ingewikkeld bij het terugvinden van de namen van de getroffenen in de patiëntendatabases van de huisartsen: dit moest handmatig gebeuren en was daarom zeer tijdrovend. Uitgangspunt was dat iedereen getroffen was die in bepaalde (delen van) straten woonde ten tijde van de ramp of die zichzelf als getroffene had gemeld bij het gemeentelijke Informatie en Advies Centrum.

\section{Resultaten}

Ieder kwartaal werd het zorggebruik en de morbiditeit uitgedraaid van ruim 3900 getroffenen en ongeveer 10.000 referenties. Deze 13.940 mensen presenteerden samen in 6,5 jaar 371.680 problemen aan hun huisarts, ofwel gemiddeld 26,7 problemen per persoon. Daarbij ging het vooral om chronische aandoeningen (een kwart van alle problemen), lichamelijk onverklaarde klachten (24\%) en psychische problematiek (11\%).

Bij de chronische aandoeningen viel vooral op dat de prevalenties van de getroffenen eerder stegen (vanaf een half jaar na de ramp en bij de referentiegroep na $1 \frac{1}{2}$ jaar) en dat een prevalentieverschil van 30-40 per 1000 bleef bestaan tot vijf jaren na de ramp. Hierbij bleek het vooral om hypertensie te gaan en om cardiovasculaire problematiek in het algemeen (Dirkzwager, Van der Velden, Grievink, \& Yzermans, 2007), om chronische aandoeningen van het bewegingsapparaat (met name de lage rug) en om diabetes mellitus.

In de eerste periode na de ramp was het aantal lichamelijk onverklaarde klachten onder de getroffenen groter dan onder de referenties, maar het verschil tussen getroffenen en 
referenties na de ramp werd vooral verklaard door al bestaande verschillen voor de ramp (Van den Berg, Grievink, Lebret, \& Yzermans, 2005; Van den Berg, Grievink, Yzermans, \& Lebret, 2005). De verschillen tussen getroffenen en referenties in zorggebruik en (een deel van de) morbiditeit vóór de ramp konden moeilijk worden verklaard, omdat beide groepen immers stonden ingeschreven bij dezelfde huisartspraktijken. De referentiegroep was bovendien gematcht voor leeftijd, geslacht en verzekeringsvorm, een proxy voor sociaaleconomische verschillen. In dit geval lijkt deze benadering te grof te zijn.

Bij de getroffenen steeg het aantal psychische problemen na de ramp met een factor 6 (van 60 per 1000 in het kwartaal voor de ramp, naar 360 per 1000 in de eerste drie maanden erna) en bij de referentiegroep in het geheel niet. Het beloop in de tijd liet een scherpe daling zien naar een prevalentie van 120 één jaar na de ramp. Als een plateau bleef deze prevalentie gehandhaafd tot vier jaren na de ramp, waarna de prevalentie zakte naar \pm 80 per 1000 (Den Ouden, Dirkzwager, \& Yzermans, 2005; Yzermans et al., 2005). Onmiddellijk na de ramp ging het daarbij vooral om slaapproblemen en het probleem 'angstig, nerveus' (en dus niet om een - gegeneraliseerde - angststoornis). Ongeveer drie jaren na de ramp ging het vooral om de depressieve stoornis. Voor lichamelijke symptomen verliep het beloop in de tijd vooral van nek- en schoudersymptomen (in het eerste jaar) naar lage rugpijn (vanaf het derde jaar). Onmiddellijk na de ramp werden veel benzodiazepines (slaap- en kalmeringsmiddelen) voorgeschreven door de huisartsen; slechts in enkele gevallen leidde dit tot chronisch gebruik (Fassaert et al., 2007).

Het gepresenteerd hebben van psychische problemen voor de ramp bleek de belangrijkste voorspeller te zijn voor psychische problemen en lichamelijke symptomen na de ramp, naast het gedwongen verhuizen/verlies van persoonlijke bezittingen. 'Normale' risicogroepen, zoals vrouwelijk geslacht, oudere leeftijd en niet geboren zijn in Nederland bleken geen extra bijdrage te hebben aan aard en omvang van de ervaren gezondheidsproblemen na de ramp (Van den Berg et al., 2008; Dirkzwager, Grievink, Van der Velden, \& Yzermans, 2006; Soeteman et al., 2007).

Omdat er geen evaluatieonderzoek werd uitgevoerd, kan niet zonder meer worden bepaald in hoeverre het beleid van het ministerie van VWS om gezondheidsonderzoek, waaronder monitoring in de huisartspraktijk, te implementeren succesvol was voor de nazorg. Het relatief geruisloze verloop van de periode na de ramp (vergeleken met de nasleep van de Bijlmerramp) en de grote aantallen mensen die weer controle over hun leven kregen suggereren dat de aanpak juist was en dat de onderzoeksresultaten behulpzaam waren bij de (kwaliteit van de) nazorg.

\section{NIEUWJAARSBRAND VOLENDAM}

\section{Onderzoeksopzet}

De ramp in Volendam vond plaats in de Nieuwjaarsnacht van 1 januari 2001. In essentie week het design van de huisartsmonitoring na de ramp niet af van het in Enschede toegepaste model. Er waren drie belangrijke verschillen:

- Omdat de server van de computers van de huisartsen bij de apotheek stond, konden ook alle voorgeschreven (en afgehaalde) medicamenten in beeld worden gebracht;

- Omdat Volendam veel kleiner is dan Enschede konden de huisartsen de getroffen patiënten in hun huisartsinformatiesysteem ten behoeve van de monitoring markeren, waardoor ouders en broers en zussen van de getroffen kinderen in de monitor konden worden betrokken. Bij de in het bewuste café, het Hemeltje, aanwezige kinderen werd onderscheid gemaakt tussen kinderen met en zonder brandwonden (Dorn, Ten Veen \& Yzermans, 2007).

- In Enschede werd door het gemeentelijke Informatie en Advies Centrum ook bijgehouden wie als passant aanwezig was bij de ramp en wie als reddingswerker was ingeschakeld. In Volendam werd dit niet als taak van het Advies en Informatie Centrum het Anker gezien. Daardoor bleef onduidelijk wie getuige was geweest en 
wie reddingswerk ondernam (Dorn, Ten Veen, \& Yzermans, 2007). De onderzoeksperiode omvatte bij dit project één jaar vóór de brand tot en met $5 \frac{1}{2} 2$ jaar erna; niet-getroffen patiënten van de huisartsen dienden, gematcht voor leeftijd en geslacht, als referentie.

\section{Resultaten}

Het zorggebruik (aantal contacten met de huisarts) was verhoogd tot drie jaren na de ramp. Dit gold voor alle groepen: kinderen met en zonder brandwonden, hun ouders, broers en zussen (Dorn, Yzermans, \& Van der Zee, 2006). Jongeren met brandwonden presenteerden gedurende de gehele onderzoeksperiode meer direct aan de ramp gerelateerde symptomen van luchtwegen (inhalatietrauma) en huid (brandwonden), meer onverklaarde lichamelijke klachten en meer chronische aandoeningen aan hun huisarts dan voor de ramp. In de eerste periode na de brand presenteerden kinderen zonder brandwonden zelfs meer psychische problemen dan kinderen met brandwonden en meer onverklaarde lichamelijke klachten. Dit gegeven dient echter met voorzichtigheid te worden geïnterpreteerd, omdat kinderen met brandwonden vaak lang in ziekenhuizen waren opgenomen en bij specialisten onder behandeling bleven; zij hadden dus minder gelegenheid hun klachten en aandoeningen aan de huisarts te presenteren. Er werden, vergeleken met de periode voor de ramp en vergeleken met de referentiegroep, nauwelijks meer chronische aandoeningen gepresenteerd door de ouders van de kinderen, hoewel nadere analyse aangaf dat er bij de ouders (vooral die van overleden kinderen) meer cardiovasculaire aandoeningen, zoals hypertensie, werden gediagnosticeerd (Dorn, Yzermans, Guijt, \& Van der Zee, 2007). Psychische problemen werden vooral gezien bij ouders van overleden kinderen (gehele onderzoeksperiode) en ouders van kinderen met brandwonden (eerste drie jaren) (Dorn, Yzermans, Kerssens, Spreeuwenberg, \& Van der Zee, 2007).

Psychofarmaca werden door jongeren met brandwonden na de ramp vaker gebruikt dan door hun Volendamse leeftijdgenoten. Ongeveer een jaar na de brand was het verschil in gebruik van benzodiazepines en antidepressiva tussen de groepen niet meer statistisch significant (Dorn, Yzermans, \& Van der Zee, 2007), terwijl het verschil voor de totale groep psychofarmaca wel significant bleef (veroorzaakt door de kleine getallen). Hierbij deed zich de discrepantie voor dat jongeren met brandwonden op langere termijn niet meer psychische problemen aan hun huisarts presenteerden dan hun leeftijdgenoten, maar wel meer psychofarmaca kregen voorgeschreven.

Het was opmerkelijk dat op langere termijn meer benzodiazepines werden voorgeschreven aan ouders van kinderen zonder brandwonden en meer antidepressiva aan ouders van kinderen met brandwonden (Dorn, Yzermans, \& Van der Zee, 2007).

Anders dan in Enschede is er in Volendam een relatief grote groep (jongvolwassenen) met chronische, aan de brand gerelateerde verwondingen. De gevolgen van het meemaken van de brand blijven een alledaagse werkelijkheid en dat blijft ook voor de ouders een bron van spanning.

\section{CONCLUSIES}

\section{Onderzoeksopzet}

De huisartspraktijk is een goede bron van longitudinale informatie over zorggebruik en gezondheidsproblemen na rampen. Het is mogelijk een vergelijking te maken tussen de periode voor en na de ramp, gebruik te maken van controle- of referentiegroepen en het onderzoek belast de getroffenen niet. Na de rampen in Enschede en Volendam werden de huisartsen eens per kwartaal op de hoogte gebracht van het beloop in de tijd van zorggebruik en morbiditeit bij hun getroffen en niet-getroffen patiënten. Deze informatie stelde de huisartsen in staat het beleid bij de behandeling van getroffen patiënten te optimaliseren. De individuele huisarts heeft immers minder zicht op laag-prevalente symptomen en aandoeningen, op beloop in de tijd van klachtenpatronen en op eigen 'witte vlekken'. 
IJzermans, J., Soeteman, R. Gezondheidsproblemen en zorggebruik na drie rampen in Nederland: monitoring in de huisartspraktijk. Psychologie \& Gezondheid: 2008, 36(3), 141-146

Omdat monitoring in de huisartspraktijk na de genoemde rampen niet snel kon starten is bij het Centrum voor Gezondheid en Milieu van het RIVM een 'stand-by unit voor gebruik maken van bestaande registraties na rampen’ ingesteld. Hier worden bovengenoemde problemen 'in vredestijd' opgelost. Twee problemen krijgen hier speciale aandacht: registratie van getroffenen en het regelen van de privacy.

In Enschede is gebleken dat een combinatie van monitoring in de huisartspraktijk met bevolkingsonderzoek waarin getroffenen zelf worden bevraagd goed werkt: beide designs vangen gecombineerd elkaars zwakke punten op. Bevolkingsonderzoek wordt uitgebreid met longitudinale gegevensverzameling met baselinegegevens (van voor de ramp), zonder 'recall bias', terwijl de huisartsenmonitoring wordt uitgebreid met (veel) meer demografische gegevens.

\section{Resultaten}

Er waren, onmiddellijk na de rampen, veel meer psychische problemen bij getroffenen en dit aantal bleef steeds verhoogd tot het eind van de onderzoeksperiode. In de eerste maanden ging het hierbij vooral om slaapproblemen, stressreacties en een angstig, nerveus gevoel, terwijl na ongeveer drie jaren de nadruk lag op moeheid, malaise en een depressieve stoornis. In Volendam en in Enschede werd een tijdelijke verhoging gevonden van het voorkomen van lichamelijk onverklaarde klachten (vooral van het bewegingsapparaat en het spijsverteringskanaal) die na enige maanden terugkeerde naar het niveau van de referentiegroep en/of de periode voor de ramp (Soeteman et al., 2006). In de Bijlmermeer kregen deze klachten een chronisch karakter, aangezwengeld door onzekerheid over de lading van het $\mathrm{El} \mathrm{Al}$ toestel en voortdurende aandacht in de media.

Vooral mensen met psychische problemen voor de ramp blijken 'at risk' te zijn voor zowel psychische problemen als lichamelijke symptomen na de ramp: zij vormen een kwetsbare groep.

\section{LITERATUUR}

Berg, B. van den, Grievink, L., Lebret, E., \& Yzermans, C.J. (2005). Medically

1. Unexplained Physical Symptoms in the aftermath of traumatic events: a review of the disaster-literature. Epidemiological Reviews, 27, 92-106.

Berg, B. van den, Grievink, L., Velden, P.G. van der, Yzermans, C.J., Stellato, R.K.,

2. Lebret, E., \& Brunekreef, B. (2008). Risk factors for physical symptoms after a disaster: a longitudinal study. Psychological Medicine, 38, 499-510.

Berg, B. van den, Grievink, L., Yzermans, C.J., \& Lebret E. (2005). Symptoms and

3. related functioning in a traumatized community. Archives of Internal Medicine, 165, 2402-2407.

Dirkzwager, A.J.E., Grievink, L., Velden, P.G. van der, \& Yzermans, C.J. (2006). Risk

4. factors for psychological and physical health problems after a man-made disaster; a prospective study. British Journal of Psychiatry, 189, 144-149.

Dirkzwager, A.J.E., Velden, P.G. van der, Grievink, L., \& Yzermans, C.J. (2007).

5. Disaster-related Posttraumatic Stress Disorder and physical health. Psychosomatic Medicine, 69, 435-440.

6. Donker, G., Yzermans, C.J., Spreeuwenberg, P., \& Zee, J. van der (2004). De ramp in de spreekkamer. Huisarts \& Wetenschap, 47, 22-25.

Donker, G., Yzermans, C.J., Oosterhek, M., Spreeuwenberg, P.P., \& Zee, J. van der

7. (2002). Symptom attribution after a plane crash: comparison between self-reported symptoms and GP-records. British Journal of General Practice, 52, 917-922.

Dorn, T., Veen, P.M.H. ten, \& Yzermans, C.J. (2007). Gevolgen van de

8. Nieuwjaarsbrand in Volendam voor de gezondheid; eindrapport van de monitoring in huisartspraktijken en apotheken. Utrecht: NIVEL.

9. Dorn, T., Yzermans, C.J., Guijt, H., \& Zee, J. van der (2007). Disaster-related stress as 
IJzermans, J., Soeteman, R. Gezondheidsproblemen en zorggebruik na drie rampen in Nederland: monitoring in de huisartspraktijk. Psychologie \& Gezondheid: 2008, 36(3), 141-146

a prospective risk factor for hypertension in parents of adolescent fire victims. American Journal of Epidemiology, 165, 410-417.

Dorn, T., Yzermans, C.J., Kerssens, J.J., Spreeuwenberg, P.M.M., \& Zee, J. van der

10. (2007). Physical and mental health problems in parents of adolescents with burns; a controlled longitudinal study. Journal of Psychosomatic Research, 63, 381-389.

Dorn, T., Yzermans, C.J., \& Zee, J. van der (2006). Disaster and subsequent health

11. care utilization, a longitudinal study among victims, their family members and controls. Medical Care, 44, 581-589.

Dorn, T., Yzermans, C.J., \& Zee, J. van der (2007) Prospective cohort study into post-

12. disaster benzodiazepine use demonstrated only short-term increase. Journal of Clinical Epidemiology, 60, 795-802.

Fassaert, T., Dorn, T., Spreeuwenberg, P.M.M., Dongen, M.C.J.M. van, Gool, C.J.A.W.

13. van, \& Yzermans, C.J. (2007). Prescription of benzodiazepines in general practice in the context of a man-made disaster: a longitudinal study. European Journal of Public Health, 17, 612-617.

Gersons, B.P.R., Carlier, I.V.E., \& Yzermans, C.J. (2000). 'In de spiegel der emoties':

14. onvoorziene langetermijngevolgen van de Bijlmer Vliegramp. Maandblad Geestelijke Volksgezondheid, 55, 876-88.

15. Lamberts, H., \& Wood, M. (1987). The International Classification of Primary Care (ICPC). Oxford: Oxford University Press.

Ouden, D.J. den, Dirkzwager, A.J.E., \& Yzermans, C.J. (2005). Health problems

16. presented to the GP in patients seeking mental health care: longitudinal data of disaster survivors. Scandinavian Journal for Primary Health Care, 23, 137-141.

Soeteman, J.H., Yzermans, C.J., Kerssens, J.J., Dirkzwager, A.J.E., Donker, G.A.,

17. Bosch, W.J.H.M. van den, \& Zee, J. van der (2006). The course of health problems following disaster. Family Practice, 23, 378-384.

Soeteman, J.H., Yzermans, C.J., Kerssens, J.J., Dirkzwager, A.J.E., Donker, G.A.,

18. Veen, P.M.H. ten, Bosch, W.J.H.M. van den, \& Zee J. van der (2007). Health problems presented in general practice one year prior to and one year following a disaster. Journal American Board of Family Medicine, 20, 548-556.

19. Vasterman, P., Yzermans, C.J., \& Dirkzwager, A.J.E. (2005). The role of the media and media hypes in the aftermath of disasters. Epidemiological Reviews, 27, 107-114.

Yzermans, C.J., Zee, J. van der, Oosterhek, M., Spreeuwenberg, P.M.M., Kerssens,

20. J.J., Donker, G.A., \& Schadé, E. (1999). Gezondheidsklachten en de Vliegramp Bijlmermeer. Amsterdam/Utrecht: AMC/NIVEL.

Yzermans, C.J., Dirkzwager, A.J.E., Kerssens, J.J., Cohen-Bendahan, C.C.C. \& Veen,

21. P.M.H. ten (2006). Gevolgen van de Vuurwerkramp Enschede voor de gezondheid; eindrapport van de monitoring in de huisartspraktijken. Utrecht: NIVEL.

Yzermans, C.J., Donker , G.A., Kerssens, J.J., Dirkzwager, A.J.E., Soeteman, J.H., \&

22. Veen, P.M.H. ten (2005). Health problems of victims before and after disaster, a longitudinal study in family practice. International Journal of Epidemiology, 34, 820826.

Yzermans, C.J. \& Gersons, B.P.R. (2002). The chaotic aftermath of an airplane crash in

23. Amsterdam: a second disaster. In J.M. Havenaar, J.G. Cwikel, \& E.J. Bromet, Toxic turmoil; psychological and societal consequences of ecological disasters (pp. 85-100). New York: Kluwer Academic/Plenum Publishers. 